\title{
Care Seeking Behaviour of Bangladeshi Migrant Workers in Sarawak, Malaysia
}

\author{
Rahman MM*, Arif MT, Safii R, Tambi Z, Akoi C, Jantan Z, Halim SA \\ Faculty of Medicine and Health Sciences, Universiti Malaysia Sarawak, Malaysia
}

\begin{abstract}
Background: Migrant workers are exposed to vulnerable health risks related to occupational safety, infection and personal health risk behaviours. These vulnerabilities, together with low capacity to pay medical care, and poor access to healthcare, can result in unsatisfactory health outcomes.

Objective: The objectives of the study were to determine the pattern of morbidity and the care seeking behaviour of Bangladeshi migrant workers in Sarawak.

Methods: This cross-sectional study was conducted among Bangladeshi migrant workers in selected districts in Sarawak, Malaysia. A total of 314 Bangladeshi workers were interviewed by face to face using a predesigned and validated questionnaire. Simple descriptive analysis was done using SPSS version 22.0. However, to supplement the quantitative findings, field notes were also analysed.

Results: The mean (SD) age of the respondents was 35.9 (7.3) years. Most of the workers were engaged in manufacturing job (43\%) followed by construction (32.2\%) and a variety of job according to the employers' desire (22.9\%). The median monthly salary of the workers was MYR 923 with median duration works was 10 years. One-fourth of the workers $(25.5 \%)$ had no health insurance, while another one tenth of workers were unaware of health insurance. It was found that $20 \%$ had medial ailments in the last two weeks, while $45.2 \%$ had physical complaints in the last one month. The most frequent complaints were fever $(48.4 \%)$ followed by injuries $(11.3 \%)$ in the last two weeks. About three fifths $(57.4 \%$ in last two weeks and $60.6 \%$ in last one month) visited private health hospitals or clinics for their treatment. Only a few workers visited public hospitals or clinics for their ailments. One-fifth of the workers were self-medicated. While another one tenth of workers visited traditional healer for their ailments. Qualitative analysis revealed a high cost and no scope of bargain as factors which discourage them to take treatment from public hospitals or clinics.
\end{abstract}

Conclusion: The majority of migrant workers in this study sought healthcare when they fell ill. However, knowledge about health-related insurance was poor and low wage might be significant issues in accessing health care services. The study concluded that workers' friendly health policy could be instituted for the welfare of the foreign workers' despite of their awareness of local health services.

Keywords: Care seeking behaviour, Migrant workers, Bangladesh, Sarawak, Malaysia

\section{Introduction}

The international migrant worker plays a vital role in many countries as a result of economic globalisation. The International Organisation of Migration (IOM) estimates that 232 million people a year become international migrants and another 740 million move within their own countries. ${ }^{1}$ Asia Pacific region has the largest flow of migrants with estimate of about 30 million migrant workers. ${ }^{2}$ In Malaysia, the total numbers of international migrant increased from 1,014,156 to 2,469,173 in 1990 and 2013 respectively. ${ }^{3}$

*Correspondence: Md. Mizanur Rahman, Faculty of Medicine and Health Sciences, Universiti Malaysia Sarawak, Malaysia; e-mail: rmmizanur@unimas.my
Majority of them are male migrants working in construction and agriculture sectors such as palm oil and rubber plantations. On the other hand, the female migrants in Malaysia work predominantly in the electronics industry and as domestic workers.

Malaysia is one of the main primary host countries in the South-East Asian region together with Thailand, Singapore and Brunei Darussalam, whereas, Cambodia, Lao PDR, Indonesia, Myanmar, Philippines and Vietnam are the main primary source countries. ${ }^{3}$ Most of the international migrants in Malaysia in 2013 are from Indonesia $(1,051,227)$ followed by Bangladesh $(352,005)$, 
Myanmar $(247,768)$, Nepal $(201,345)$ and India $(130,320)$. These 5 countries had contributed to about $80.3 \%$ of the Malaysia total international migrants in 2013. It is estimated that $54 \%$ of documented workers work in manufacturing, $20 \%$ in agriculture, $14 \%$ in construction and $12 \%$ in the service sector. The percentage of international migrants out of total migration in Sarawak had shown a reduction from $27.3 \%$ during 2014-2015 to $18.6 \%$ during $2015-2016 .{ }^{4}$

The first group of Bangladeshi labourers in Malaysia was in 1986. They worked as plantation workers. Later, they were allowed to work in different sectors after both countries signed a bilateral agreement in 1992. Although they have been providing excellent services and performing well in all sectors of development, they often face difficulties and constraints with regard to their health and hygiene. The Bangladeshi migrants frequently suffer from illnesses such as fever, jaundice, piles, asthma, gallstone, back pain, tumours, eye problem and ulcer. ${ }^{5,6}$ However, most of the cases, their health-seeking behaviour was unexplored. Health-seeking behaviour refers to the individual act to prevent diseases and to detect diseases in asymptomatic stages, because of they perceive themselves as ill or having health problem. This behaviour among migrant workers is significantly related to the socio-economic development, gender and culture. ${ }^{7,8}$ Furthermore, the universal access which includes the cost of treatment and attitude of the healthcare provider and culturally competent health care services are also important to provide a good access to health services. ${ }^{89}$ There were few studies conducted over the pattern of morbidity among the migrant workers especially in Malaysia. Hence, the present study was aimed to assess the pattern of morbidity and their care seeking behaviour of Bangladeshi migrant workers in Sarawak, Malaysia.

\section{Materials and Methods}

This was a cross sectional quantitative descriptive study to explore the pattern of morbidity and care seeking behaviour among the Bangladeshi workers in Sarawak, Malaysia. The target population for this survey included all men aged 18 years and above living in their primary place of residence. To get a good estimate of care seeking behaviour, $36.4 \%$ prevalence of morbidity was considered as the base prevalence for calculation of sample size with margin of error $0.03 .^{10,11}$ The estimated sample size was 401 with a non-response rate of $10 \%$. However, only 329 workers were managed to interview with a response rate of $82 \%$.

A data collection instruments was developed based on Patient Satisfaction Questionnaire, and other previous instruments. ${ }^{12-14}$ The questionnaire had several components viz. socio-demographic characteristics, morbidity pattern, care seeking behaviour, perception on health care delivery system and acculturation process. Before the field operation, the questionnaire was pre-tested in the non-sample area. The entire questionnaire was developed into English and translated into Bangla for field operation. During data collection, a snow balling technique was adopted with an identification of a key person and then interview was undertaken in their place of residence. Data collection was done in the weekends. A Bangladeshi university student was recruited for data collection. All the data were verified by the research team leader, who also took the field notes regarding the care seeking behaviour and preference of treatment.

After data collection, each questionnaire was verified and manually edited by the interviewer. Any missing or non-response questions were crosschecked on the spot. A total of 15 respondents were denied to be interviewed due to work pressure and other commitment. A total of 314 data entry was done using Microsoft Excel 2016. The data was imported into SPSS version 22.0 for analysis. Missing value analysis was done first and then imputed the missing value using regression methods. ${ }^{15}$ A simple descriptive analysis was done. The results were presented in frequency tables with 95\% bias corrected confidence interval using bootstrapping methods to get the precise results. ${ }^{15}$

The research proposal was approved by the technical review committee of Faculty of Medicine and Health Sciences (FMHS) and Institute of Borneo Studies (IBS) of Universiti Malaysia Sarawak (UNIMAS). The Ethical approval was also obtained from the Ethics Committee of Universiti Malaysia Sarawak (UNIMAS) [(UNIMAS/NC-21.02/03-02(13)]. The participants were briefed about the purpose of data collection and their voluntary participation were sought. They 
were also assured of data confidentiality. A written informed consent was taken before an interview.

\section{Results}

The frequency distribution with bias corrected 95\% confidence interval of socio-demographic characteristics of the migrant workers (table I). The mean (SD) age of the respondents was 35.9 (7.3) years with the minimum 24 years and maximum 60 years. Nearly half $(48.7 \%)$ of the workers were in the age group 30-39 years. Nearly 100 percent were Muslim (98.1\%). Majority of the workers were married (84.7\%). Highest percentage $(43.3 \%)$ had secondary level of education followed by primary level of education (33.8\%). However, $15.6 \%$ had no formal education. Highest percentage of the workers were engaged in manufacturing job (43\%) followed by construction (32.2\%) and a variety of job according to the employer desire (22.9\%). Very few of them were engaged in agriculture farming $(1.9 \%)$. It was found that $82.2 \%$ of the workers works on a daily paid basis and only $17.8 \%$ had monthly salary. The median monthly income of the workers was MYR 923 with maximum MYR 2000 and minimum MYR 520. More than half of the worker had monthly income ranges from MYR 900 to 1300. Each worker had at least 4 members' dependant on him with a maximum 10 and minimum one member. The median duration of working in Malaysia was 10 years with maximum 21 years and minimum one year. More than three fifths $(62.4 \%)$ of the workers had 10 to 14-year work experience. Majority of the workers (94.6\%) had no previous work experience abroad. It was noted that $84.1 \%$ were living in shared room. About two-thirds (63.4\%) had health insurance in Sarawak. However, $25.5 \%$ had no health insurance. One third (36.6\%) of the workers reported that the employer did not bear any medical costs and twofifths (41.1\%) bear partial cost and another 22.3\% bears all types of costs.

Table I: Socio-demographic characteristics of the migrant workers

\begin{tabular}{|c|c|c|c|c|}
\hline \multirow{2}{*}{ Characteristics } & \multirow{2}{*}{ Frequency } & \multirow{2}{*}{$\begin{array}{c}\text { Percent/ } \\
\text { Mean }\end{array}$} & \multicolumn{2}{|c|}{$95 \% \mathrm{CI}$} \\
\hline & & & Lower Limit & Upper Limit \\
\hline Age in years (Mean, $S D)$ & 314 & $35.9(7.3)$ & 35.0 & 36.9 \\
\hline \multicolumn{5}{|l|}{ Religion } \\
\hline Islam & 308 & 98.1 & 96.8 & 99.4 \\
\hline Hinduism & 6 & 1.9 & 0.6 & 3.5 \\
\hline \multicolumn{5}{|l|}{ Marital status } \\
\hline Single & 48 & 15.3 & 11.5 & 19.1 \\
\hline Married & 266 & 84.7 & 80.9 & 88.5 \\
\hline \multicolumn{5}{|l|}{ Level of education } \\
\hline No formal education & 49 & 15.6 & 12.4 & 19.1 \\
\hline Primary & 106 & 33.8 & 29.0 & 38.4 \\
\hline Secondary & 136 & 43.3 & 37.6 & 48.7 \\
\hline Higher secondary & 23 & 7.3 & 4.8 & 10.0 \\
\hline \multicolumn{5}{|l|}{ Nature of job } \\
\hline Farming & 6 & 1.9 & 0.6 & 3.5 \\
\hline Construction & 101 & 32.2 & 27.7 & 36.9 \\
\hline Manufacturing & 135 & 43.0 & 37.7 & 48.4 \\
\hline Others & 72 & 22.9 & 18.8 & 27.7 \\
\hline \multicolumn{5}{|l|}{ Type of salary payment } \\
\hline Daily & 258 & 82.2 & 78.0 & 86.6 \\
\hline Monthly & 56 & 17.8 & 13.7 & 21.7 \\
\hline Median Monthly income $(\mathrm{RM})$ & 314 & 923.0 & 920.0 & 948.0 \\
\hline Number of dependant (Median) & 314 & 4.0 & 4.0 & 5.0 \\
\hline Duration of work in Malaysia (Yrs) & 314 & 10.0 & 10.0 & 11.0 \\
\hline \multicolumn{5}{|l|}{ Working experience other than Malaysia } \\
\hline Yes & 17 & 5.4 & 3.2 & 7.6 \\
\hline No & 297 & 94.6 & 92.4 & 96.8 \\
\hline \multicolumn{5}{|l|}{ Living condition } \\
\hline Shared & 264 & 84.1 & 80.6 & 87.6 \\
\hline Single room & 50 & 15.9 & 12.1 & 20.1 \\
\hline \multicolumn{5}{|l|}{ Ever take sick leave } \\
\hline Yes & 58 & 18.5 & 14.6 & 22.0 \\
\hline No & 256 & 81.5 & 78.0 & 85.4 \\
\hline \multicolumn{5}{|l|}{ Health insurance in Sarawak } \\
\hline Yes & 199 & 63.4 & 58.6 & 68.2 \\
\hline No & 80 & 25.5 & 20.7 & 30.6 \\
\hline No idea & 35 & 11.1 & 8.0 & 14.3 \\
\hline \multicolumn{5}{|l|}{ Whether company bear treatment cost } \\
\hline Never & 115 & 36.6 & 31.8 & 42.0 \\
\hline Partial & 129 & 41.1 & 35.7 & 46.2 \\
\hline All types of cost & 70 & 22.3 & 18.2 & 27.1 \\
\hline
\end{tabular}


The self-reported morbidity pattern in the two weeks and one month. It was found that $80.3 \%$ had no complaints in the last two weeks and $54.8 \%$ had no complaints in the last one month (table II). The most frequent complaints were fever (48.4\%) followed by injuries (11.3\%) in the last two weeks. Similar pattern of complaints was found in the last one month in which the highest percentage was fever $(61.3 \%)$ followed by gastrointestinal complaints $(10.6 \%)$.

Table II: Percentage distribution of respondents by their pattern of illness

\begin{tabular}{ccccc}
\hline \multirow{2}{*}{$\begin{array}{c}\text { Pattern of } \\
\text { disease/illness }\end{array}$} & \multicolumn{2}{c}{$\begin{array}{c}\text { Last two } \\
\text { weeks(n=62) }\end{array}$} & \multicolumn{2}{c}{$\begin{array}{c}\text { Last one } \\
\text { month(n=142) }\end{array}$} \\
\cline { 2 - 5 } & Frequency & $\mathbf{\%}$ & Frequency & $\mathbf{\%}$ \\
\hline Chronic disease & $\mathbf{1 2}$ & $\mathbf{3 . 8}$ & $\mathbf{1 3}$ & $\mathbf{4 . 1}$ \\
Blood pressure & 2 & 3.2 & 3 & 2.1 \\
Diabetes & 1 & 1.6 & 1 & 0.7 \\
Muscle pain & 2 & 3.2 & 4 & 2.8 \\
Joint pain & 2 & 3.2 & 4 & 2.8 \\
Others & 5 & 8.1 & 1 & 0.7 \\
Acute disease & $\mathbf{1 8}$ & $\mathbf{5 . 7}$ & $\mathbf{3 0}$ & $\mathbf{9 . 6}$ \\
Fracture & 1 & 1.6 & 0 & 0.0 \\
GI disease & 2 & 3.2 & 15 & 10.6 \\
Burn & 1 & 1.6 & 0 & 0.0 \\
Sprain & 7 & 11.3 & 8 & 5.6 \\
Other injuries & 7 & 11.3 & 7 & 4.9 \\
Minor ailments & $\mathbf{3 2}$ & $\mathbf{1 0 . 2}$ & $\mathbf{9 9}$ & $\mathbf{3 1 . 5}$ \\
Fever & 30 & 48.4 & 87 & 61.3 \\
Flu & 1 & 1.6 & 4 & 2.8 \\
Conjunctivitis & 0 & 0.0 & 6 & 4.2 \\
Others & 1 & 1.6 & 2 & 1.4 \\
No complaints & $\mathbf{2 5 2}$ & $\mathbf{8 0 . 3}$ & $\mathbf{1 7 2}$ & $\mathbf{5 4 . 8}$ \\
\hline
\end{tabular}

About three fifths (57.4\%) visited private hospital or clinic for their treatment in the last two weeks and $60.6 \%$ in the last one month. Very limited number of workers visited public hospital or clinic for their ailments. One-fifths of the workers selfmedicated. While, more than one tenth $(12 \%)$ of workers went to traditional healer for their ailments.

Table III: Percentage distribution of respondents by their pattern of care seeking behaviour

\begin{tabular}{lcccc}
\hline \multirow{2}{*}{ Place of treatment } & \multicolumn{2}{c}{ Last two weeks } & \multicolumn{2}{c}{ Last one month } \\
\cline { 2 - 5 } & $\mathbf{n = 5 4}$ & $\mathbf{\%}$ & $\mathbf{n = 1 4 2}$ & $\mathbf{\%}$ \\
\hline Public & 9 & 16.7 & 7 & 4.9 \\
Private & 31 & 57.4 & 86 & 60.6 \\
Traditional & 3 & 5.6 & 17 & 12.0 \\
Self-medication & 11 & 20.4 & 32 & 22.5 \\
\hline
\end{tabular}

\section{Discussion}

This study tried to assess the pattern of morbidity among the Bangladeshi migrant workers in Sarawak, as there are limited studies on the migrant workers in Sarawak. Migrants workers are vulnerable to illnesses, serious abuse and exploitation at workplaces resulting in the high possibility of working in hazardous jobs. Many migrants are more likely to live in overcrowded environments and substandard housing with poor sanitation which expose them to disease especially the infectious diseases. Thus, good access to healthcare services in the host country is vital for them to get early and comprehensive treatment as enjoyed by local counterparts. ${ }^{6,16}$

More than half of the respondents in this study had no complaint of any illness in the last two weeks and one-month period. The most common complaints were minor ailment and acute disease in both periods of time. Fever being the main symptoms reported by the respondents is consistent with previous study. ${ }^{6}$ Acute upper respiratory tract infection was the most common self-reported disease among migrants in Shenzhen, China. ${ }^{17}$ Lee et al stated that fever and respiratory symptoms were the main illnesses among the migrants in Singapore. ${ }^{18}$ However, there might be some misperception towards the severity of their illness as most of them (92.7\%) had secondary level of education and below. This would affect their health-seeking behaviour as they may not seek treatment for minor illness as they may assume the healthcare system in the host country is not favourable to them. In fact, the main reason for not seeking medical care is the perception of nonseriousness of the symptoms of an illness. ${ }^{16}$ This might have resulted in adverse outcome due to late diagnosis and intervention as opposed to early health care seeking action.

This study also showed that less than $20 \%$ of the respondents had ever taken sick leave. This might be due to either they did not fall sick or they might be practising self-medication ${ }^{16}$ or seeking other alternative treatment modalities whenever they become ill and subsequently able to resume their duty as usual. Informal discussion with workers revealed that they believe that employers control those who take sick leave by holding their passport. Similar was reported by Reiko or control workers by holding their passports. ${ }^{19,20}$ This might be caused the worker to reluctant to seek treatment. The passport issue had resulted in fear to be arrested by police among the migrant worker if they seek treatment in the government hospital and clinic. In addition, most of them earned daily income in which some employer may refuse to pay them if they are absent from work even though they are 
prescribed sick leave from any an authorised medical practitioner. This may further prevent them from seeking medical treatment and taking sick leave.

Only one fifth $(22.3 \%)$ of the respondents claimed that the company bear their cost of treatment. This is supported by previous studies, where merely $21 \%$ of their respondents were supported by their employers for their health treatment. ${ }^{6,21}$ Most of the migrant workers have to pay for their own treatment cost. The lower income workers had the least confidence that their company would be responsible for their medical expenses and thus make them more concern about their financial affordability of care. Some of the employers were not willing to pay for the consultation and medication for their workers especially if the illness is not related to workplace injuries. ${ }^{18,22}$

This study had found that the majority of the respondents had health insurance $(63.4 \%)$. This is far better than the finding of a study by Lee et al. ${ }^{18}$ that was conducted at all-male dormitory for migrant workers that was located near a major industrial area in Jurong, Singapore. The study discovered that only $29 \%$ of the migrant workers in Singapore were aware of the healthcare insurance plan existent for their employment in that country. This may be contributed by their poor knowledge and ignorance of the local law. ${ }^{23}$ Furthermore, most of the respondents in this study (94.6\%) have never had any experience working in other countries except in Malaysia. This may contribute towards the difficulty to familiarise with the healthcare system in the host country as it is different from the system on their country of origin. However, a majority of them had been working in Malaysia for 10 to 14 years $(62.4 \%)$ which should be sufficient for them to understand and be familiar with the system. This may indicate that the migrants are not properly informed by both the governments and also by their employers resulting low in awareness over their rights. More efforts would need to help these migrants to get a better access and affordable health care services.

About three-fifths of the respondents (57\%) in this study choose the private healthcare facilities as their main choices for place of treatment. Furthermore, a limited number of them seek treatment for their illnesses in public hospitals or clinics. One of the possible reasons for this is the frustration among the migrants over the hassles at the government hospitals such as being asked many questions about their jobs and authenticity by the healthcare staff. ${ }^{6}$

The male migrants in Singapore also prefer private practitioner and workplace doctors to the government clinics and hospitals. ${ }^{18}$ These preferences may be further aggravated by the abolishment of the subsidized healthcare for the foreigners in the public healthcare facilities in Malaysia. Thus, they would look for any alternative private healthcare facilities that provide cheaper services. Long waiting time in government facilities had resulted in the less interest of the migrants towards utilizing the healthcare services there as it may affect their working hours. ${ }^{16}$

Self-medication and seeking treatment from traditional healers are other popular health seeking behaviour among the respondents in this study. This is probably due to the relatively cheaper cost of treatment as well as less tendency to affect their working hours. Some of them may want to avoid unnecessary high healthcare cost by waiting to see whether their condition become worse and not responded to these efforts or vice versa. This is very risky as they might develop severe complication unnecessarily due to late treatment. Most migrant worker prefers the pre-packaged western medicine to the traditional medicine for their self-medication. This is consistent with the finding of this study where self-medication is the more preferred pattern of care seeking behaviour compared to visiting the traditional healers. The Bangladeshi workers also tend to bring along some emergency medicines from their country of origin for their future needs. ${ }^{6,16}$

This research has several limitations. The study was restricted to only one nationality of male migrant workers and in one state in Malaysia. So, the generalisability of the findings would be affected. Most of the workers were reluctant to fully disclose their personal behaviour and health problems which might be a possible bias in assessing morbidity pattern. The main strength of this study is that face to face interview method was done by interviewers of the same nationality as the respondents using their own language. This helps in engaging a good rapport with the respondents for a more reliable 
response. The respondents were also interviewed in their place of residence which further facilitates better and non-threatening response.

\section{Conclusion}

In conclusion, one fifths of the migrant workers had complaints of minor to major ailments. Most of them prefer to get treatment form private facilities by which may be contributed by inadequate knowledge about healthcare insurance and low wage. Therefore, better promotion and access to health information among migrant workers are recommended. Furthermore, the welfare of foreign workers can be improved through workers' friendly health policy.

\section{Acknowledgement}

The authors would like to thank to the Institute of Borneo Studies (IBS) for fund (Geran no. FO5/(NRC)/1335/2016(1)) and Faculty of Medicine and Health Sciences (FMHS), Universiti Malaysia Sarawak (UNIMAS) for approval and fund for the research. Special thanks are offered to the respondents and to the data collector.

\section{References}

1. Travis A. Migrants, refugees and asylum seekers: what's the difference? The Guardian. https://www.theguardian.com/world/2015/aug/28/mig rants-refugees-and-asylum-seekers-whats-thedifference. Published August 28, 2015. Accessed January 13, 2019.

2. Lasimbang HB, Tong WT, Low WY. Migrant Workers in Sabah, East Malaysia: The Importance of Legislation and Policy to Uphold Equity on Sexual and Reproductive Health and Rights. Best Pract Res Clin Obstet Gynaecol. 2016; 32:113-123.

doi:10.1016/j.bpobgyn.2015.08.015

3. United Nations. Migration Profiles (Malaysia) Common Set of Indicators. United Nations Organization: Population Division and UNICEF; 2014:4. https://esa.un.org/miggmgprofiles/indicators/ files/Malaysia.pdf.

4. Department of Statistics, Malaysia. Migration Survey Report, Malaysia, 2016. Department of Statistics, Kuala Lumpur;2017:2. https://www.dosm. gov.my/v1/index.php? r=column/ pdfPrev\&id= RldLdXFnQUppe GM5Yk1HODITMV16UT09.

5. Karim AZ, Diah NM, Mustari S, Sarker MSI. Work Performances and Adaptability of the Bangladeshi Workers in Malaysia. a Socio-Anthropological Study.
In: South Asian Anthropologists. Kuala Lumpur; 2013. http://irep.iium.edu.my/43665/1/Paper_for_South_Asi an_Anth.pdf.

6. Karim AZ, Diah NM. Health Seeking Behavior of the Bangladeshi Migrant Workers in Malaysia: Some Suggestive Recommendations in Adjustive Context. Asian Soc Sci. 2015; 11: 348- 357. doi: 10.5539/ ass.v11n10p348

7. MacKian S. A Review of Health Seeking Behaviour: Problems and Prospects. 2016. https://assets.publishing.service.gov.uk/media/57a08d 1de5274a27b200163d/05-03_health_seeking_ behaviour.pdf.

8. Afolabi MO, Daropale VO, Irinoye AI, Adegoke AA. Health-Seeking Behaviour and Student Perception of Health Care Services in a University Community in Nigeria. Health (N Y). 2013; 05:817-824. doi:10.4236/health.2013.55108

9. Zimmerman C, Kiss L, Hossain M. Migration and Health: A Framework for 21st Century Policy-Making. PLoS Med. 2011; 8:e1001034. doi:10.1371/journal.pmed.1001034

10. Peng Y, Chang W, Zhou H, Hu H, Liang W. Factors Associated with Health-Seeking Behavior Among Migrant Workers in Beijing, China. BMC Health Serv Res. 2010; 10:69. doi:10.1186/1472-6963-10-69

11. Wejnert C, Pham H, Krishna N, Le B, DiNenno E. Estimating Design Effect and Calculating Sample Size for Respondent-Driven Sampling Studies of Injection Drug Users in the United States. AIDS Behav. 2012; 16:797-806. doi:10.1007/s10461-012-0147-8

12. Rahman MM, Shahidullah M, Shahiduzzaman M, Rashid HA. Quality of Health Care from Patient Perspectives. Bangladesh Med Res Counc Bull. 2002; 28:87-96.

13. Kapusta J, Schöffel L, Gogolishvili D, Globerman J. Rapid Response Service. Migrant Farm Workers and Sexual Health. 2013. https://pdfs.semanticscholar.org/ 96d0/25f86ac1fcfa88c0e7166a79d8779cd69ae4.pdf.

14. Thanavanh B, Rashid MHO, Kasuya H, Sakamoto J. Knowledge, Attitudes and Practices Regarding Hiv/Aids Among Male High School Students in Lao People's Democratic Republic. J Int AIDS Soc. 2013; 16:17387.

15. IBM SPSS. IBM SPSS Statistics for Windows. Armonk, New York, USA: IBM SPSS; 2013.

16. Naing T, Geater A, Pungrassami P. Migrant Workers' Occupation and Healthcare-Seeking Preferences for Tb-Suspicious Symptoms and Other Health Problems: A Survey Among Immigrant Workers in Songkhla Province, Southern Thailand. BMC Int Health Hum Rights. 2012; 12:22. doi:10.1186/1472-698X-12-22 
17. Mou J, Cheng J, Zhang D, Jiang H, Lin L, Griffiths SM. Health Care Utilisation Amongst Shenzhen Migrant Workers: Does Being Insured Make a Difference? BMC Health Serv Res. 2009; 9:214. doi:10.1186/1472-6963-9-214

18. Lee W, Neo A, Tan S, et al. Health-seeking behaviour of male foreign migrant workers living in a dormitory in Singapore. BMC Health Serv Res. 2014; 14:300. doi:10.1186/1472-6963-14-300

19. Harima R. War on Want: Restricted Rights: Migrant Women Workers in Thailand, Cambodia and Malaysia. London: Managing Director of the Asian Migrant Centre; also Regional Coordinator of the Mekong Migration Network; 2012:36. https://waronwant.org/ sites/default/files/Restricted\%20Rights.pdf.
20. Varia N. Slow Reform: Protection of Migrant Domestic Workers in Asia and the Middle East. New York, NY: Human Rights Watch; 2010.

21. Noh NA, Wahab HA, Bakar Ah SHA, Islam MR. Public Health Services for Foreign Workers in Malaysia. Soc Work Public Health. 2016; 31:419-430. doi:10.1080/19371918.2015.1125321

22. Amnesty International. Trapped: The Exploitation of Migrant Workers in Malaysia. London, United Kingdom: Amnesty International; 2010:103. https://www.amnesty.org/download/Documents/3600 0/asa280022010en.pdf.

23. Wei WM, Yazdanifard R. The Review of Challenges Foreign Workers Face in Construction Industry of Malaysia. Glob J Manag Bus Res Adm Nd Manag. 2015; 15:13-16. 